\title{
Study on Satisfaction Levels among Hearing Aid Users in Gangetic Plains
}

https://doi.org/10.47210/bjohns.2020.v28i3.286

Bipin Kishore Prasad, ${ }^{1}$ Abhijit Basu, ${ }^{1}$ Ajay Kumar Rai ${ }^{2}$

Introduction

ABSTRACT

Outcome assessments have emerged as an effective method for determining whether or not hearing aids are working to achieve positive results in rehabilitating the hearing impaired. Present study aims to assess the satisfaction level of clientele using hearing aids.

Material and Methods

One hundred and fourteen (114) hearing handicapped patients, fitted with government-provided hearing aids at various clinics spread over Gangetic plains were included in this prospective observational study for outcome analysis. Follow up was done at 2 weeks and 45 days when they were further motivated to continue using the aid, comfortable fitting of mould was ensured along with minor trouble shooting. Four and half months later, their satisfaction level was assessed by analysing their response to Clientele Satisfaction Questionnaire.

$\underline{\text { Results }}$

Fifty percent of the patients were motivated by their family members to try the aid whereas $50 \%$ were self motivated. Better communication with family members and immediate social circle was the common motive. Majority (85\%) reported high level of satisfaction in terms of hearing benefit. Patients with severe degree of hearing loss were more satisfied and used the aid for longer duration in a day. Handling the aid was not as much of a problem as tolerating the noise produced by aid itself. Cost of battery was a concern for $80 \%$ of our clientele.

Conclusion

Proper fitting of hearing aid improved the quality of life of majority of our hearing handicapped clientele by overcoming their psychosocial problems.

$\underline{\text { Keywords }}$

Outcome Assessment; Hearing Aids; Personal Satisfaction; Surveys and Questionnaires; Quality of Life; Hearing Loss, Sensorineural

I $\mathrm{n}$ the current consumer-driven era of health care, health professionals need to be able to demonstrate, to both the community and resource providers, that the services they provide have a positive impact on their clients' functional status and quality of life. ${ }^{1}$

In audiological rehabilitation settings, outcome measures have emerged as effective method for determining whether or not specific interventions such as hearing aids (HA) are working to achieve positive results for clients. ${ }^{2}$

A study was hence undertaken to evaluate the outcome of fitting of hearing handicapped patients from Gangetic plains with HA by assessing their satisfaction level regarding hearing benefit and betterment of quality of life.

The aim of the study was to assess the satisfaction level of consumers using HA. The objectives were (a) to assess the benefit of HA use (b) to assess the constraints in using the HA and (c) to assess the difficulties in using HA.

1 - Department of ENT and HNS, Command Hospital (Eastern Command), Kolkata

2 - Department of ENT and HNS, Military Hospital,

Wellington, Tamilnadu

Corresponding author:

Dr Bipin Kishore Prasad

email: bkp1405@gmail.com 


\section{Materials and Methods}

The study design was a prospective observational study for outcome analysis. It was conducted in a tertiary care ENT centre of Armed Forces Medical Services of India over 2 years (Sep 2016 to Sep 2018). Participants of the study were selected from the population of hearing handicapped patients who had been fitted with a government-provided HA at various clinics spread over Gangetic plains of India. They included serving soldiers and their dependents as well as veterans and their dependents. All participants were fitted with HA according to Govt. of India guidelines for issue of hearing aids.

The patients with hearing loss of more than $40 \mathrm{~dB}$ at frequencies $500 \mathrm{~Hz}$ to $4000 \mathrm{~Hz}$ or with sensorineural hearing loss (SNHL) equal to or worse than $30 \mathrm{~dB}$ in their better ear (averaged over 500, 1000, 2000 and $4000 \mathrm{~Hz}$ ), willing to use HA and be a part of the study and also capable of responding to written questionnaire by themselves or by assistance were included in the study. The patients with middle ear disease, fluctuating or rapidly progressing hearing loss and with the history of previous HA use were excluded from the study.

HA type or their technological features were not considered as confounding factors in this study because they were similar for majority of the subjects. HA fitting and follow up process typically involved at least 4 sittings:

1. While prescribing the type of HA, the initial assessment steps included ascertaining the severity of hearing loss, diagnosing the type of hearing loss, determining the patient's listening needs, discussing the patient's job requirement, examining the special needs of the patient and gauging the patient's dexterity to handle the hearing aid.

2. HA was selected based on the above five factors. The patient was then made to wear the selected types of HA of different make and model which satisfy his/her listening needs. Selected types included Behind the ear, (BTE), In the canal (ITC) or Completely in canal (CIC). The patient was subjected to one to one conversation, group listening, crowd exposure and watching television. The one which gave maximum hearing benefit and minimum discomfort under the given circumstances was finally chosen. The impression of the contour of patient's external auditory canal was taken for making the ear mould for the chosen aid.

3. HA fitting involved a well designed process including fitting the HA with its ear mould, achieving appropriate amplification through the use of coupler measurement, real ear insertion gain and by measuring the aided response, educating the client in how to manage and care for their HA and providing the patient with an appropriate listening program to meet goals established in the prior appointment.

4. Follow up: First follow up at two weeks was done for motivating the patients to continue using HA and ensuring comfortable fitting of the mould. Second follow up, was done one month after the first one, i.e. 45 days after the HA fitting. It was done to further motivate them to continue using the HA and any other minor trouble shooting if necessary. During the third follow up, four and half months after HA fitting, their satisfaction levels were assessed by asking them to complete the Clientele Satisfaction Questionnaire. Literate individuals completed the questionnaire themselves. Illiterate individuals were assisted by one of the close family members.

Table I: Age and gender distribution

\begin{tabular}{|c|c|c|c|c|c|c|c|c|c|c|}
\hline $\begin{array}{c}\text { AGE GROUP } \\
\text { (YEARS) }\end{array}$ & $01-05$ & $06-10$ & $11-20$ & $21-30$ & $31-40$ & $41-50$ & $51-60$ & $61-70$ & $71-80$ & TOTAL \\
\hline Male & 6 & 0 & 0 & 1 & 2 & 0 & 16 & 33 & 8 & 66 \\
\hline Female & 2 & 1 & 0 & 1 & 0 & 2 & 13 & 29 & 0 & 48 \\
\hline Number & 8 & 1 & 0 & 2 & 2 & 2 & 29 & 62 & 8 & 114 \\
\hline
\end{tabular}




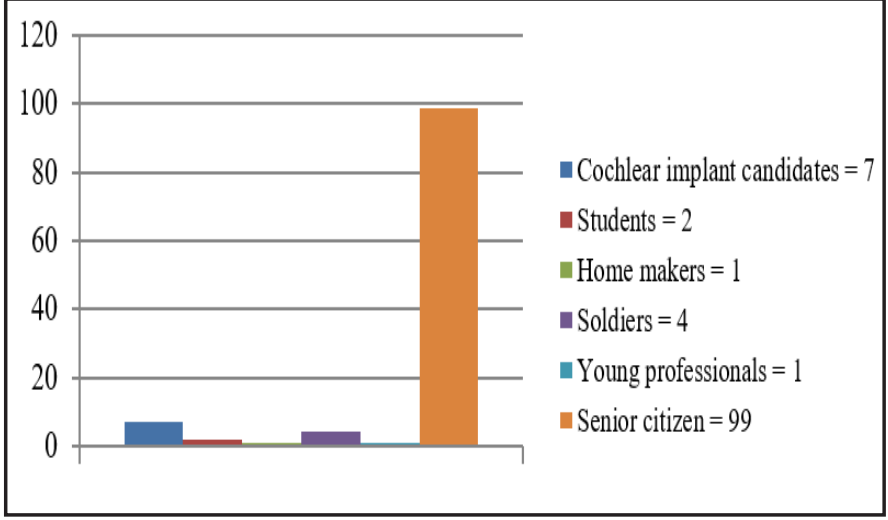

Fig. 1. Distribution of individual status

\section{Results}

Total of 114 patients were fitted with HAs. Majority were in the age group of 61 to 70 years and were suffering from Presbyacusis. There were 66 males $(58 \%)$ and 48 females $(42 \%)$. (Table I)

Cochlear implantation candidates were 7 in number and were excluded from the study because questionnaire was not suitable for them. Nine patients were lost to follow up; one soldier was transferred out to a North Eastern state, 3 patients died of old age and another 5 were not traceable after fitting the aid, thus making the final count of participants $98(n=98)$. (Fig. 1)

Grade of hearing impairment based on corresponding audiometric ISO values in decibel on four frequency average of PTA. (Fig. 2)

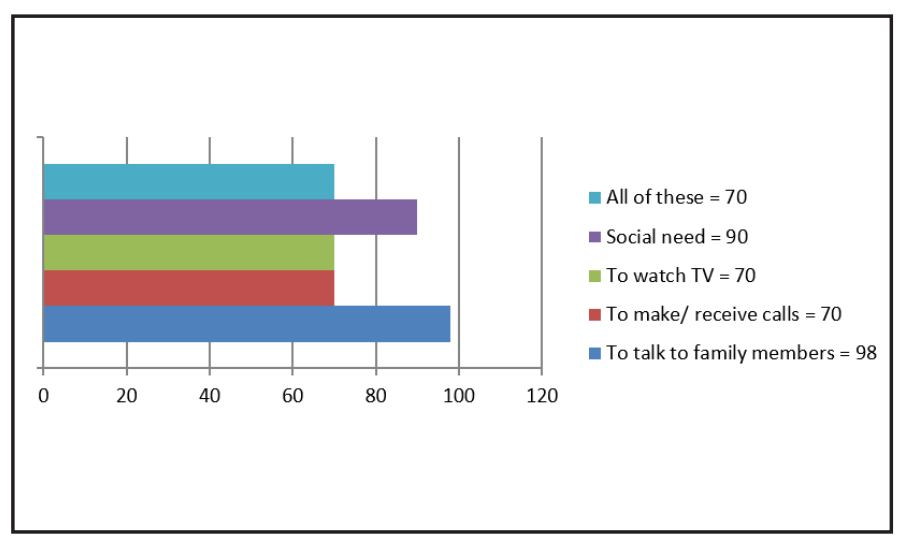

Fig. 3. Perceived need for HA use

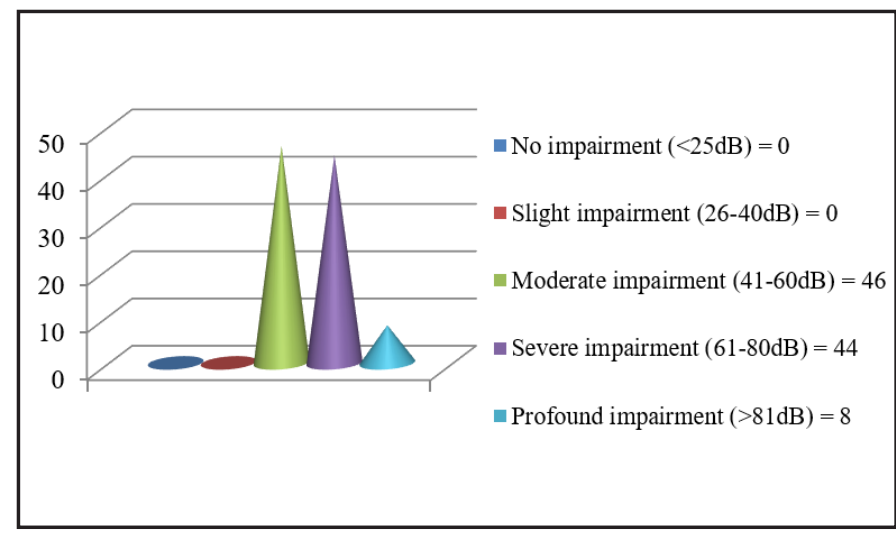

Fig. 2. Distribution as per degree of hearing impairment

To the question as to why they needed HA, majority wanted ease in talking to family members and on telephones, watching television and socializing in their limited social group. (Fig. 3)

Fifty percent individuals were self motivated whereas equal percentage were motivated and nudged by others to try the aid. All of them were satisfied with the standard of trial done before fitting the HA. Almost all of them admitted that the price of battery is high though majority were prepared to bear the cost. Majority (71\%) were using the HA for less than $6 \mathrm{hrs}$. Younger individuals, because of their need, were using the hearing aid for more than 12 hours. Twenty patients with severe hearing impairment used the aid for 6 to 12 hours. (Fig. 4)

All the patients wanted their hearing aid to be checked for its noise and 18 of them wanted reduction of the

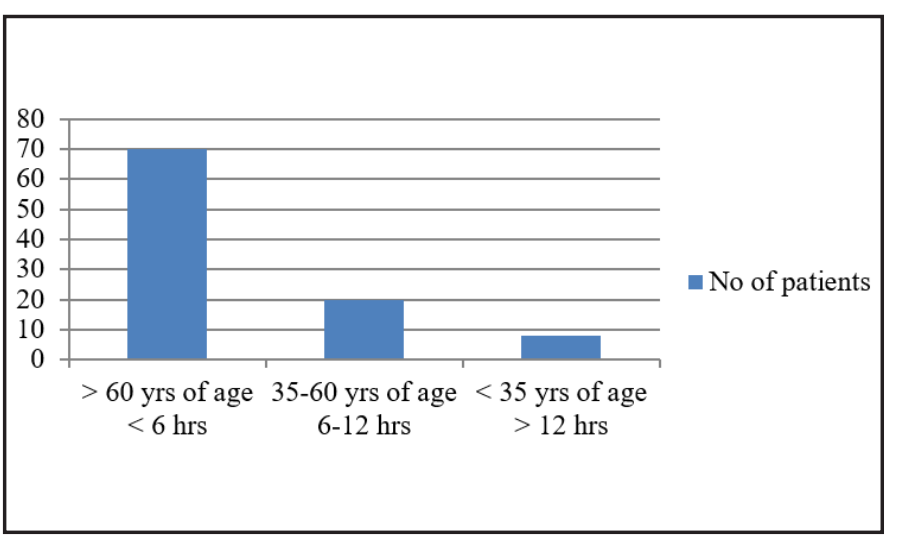

Fig. 4. Duration of use of HA by different age groups 
Table II: Perceived benefits of HA use

\begin{tabular}{|c|c|c|c|c|}
\hline BENEFIT OF USING HA & \multicolumn{5}{|c|}{ DEGREE OF BENEFIT } \\
\hline Talking to family members & Excellent & Good & Satisfactory & No benefit \\
\hline making/receiving telephone calls & Excellent & Good & Satisfactory & No benefit \\
\hline Watching TV & Excellent & Good & Satisfactory & No benefit \\
\hline Conversation in small groups & Excellent & Good & Satisfactory & No benefit \\
\hline Hearing in crowd & Excellent & Good & Satisfactory & No benefit \\
\hline Hearing in place of worship & Excellent & Good & Satisfactory & No benefit \\
\hline$n$ & 9 & 17 & 59 & 13 \\
\hline
\end{tabular}

ambient noise. Apart from 13 patients who reported no benefit from using the aid, others did not complain of any deterioration in the functioning of the aid over 4 months and they were ready to motivate other hearing impaired individuals to use the HA.

Hearing benefit for various important common activities was compared between individuals in the scale of their response as excellent, good, satisfactory and no benefit. (Table II) Most of them were only 'just' satisfied with their accrued benefit.

The difficulties faced by the patients in handling the aid, problems with mould, its noise and echo were also assessed. (Table III) Biggest irritating factor was found to be the whistling noise produced by the hearing aid.

Many of them were not conversant with the features of the HAs they were fitted with. The first follow up after 2 weeks of fitting the aid was most helpful in making them more aware about features. Many of them were not satisfied with noise cut which needed fine tuning but majority of them expressed dissatisfaction with the battery life. (Table IV)

At the end of survey, when asked whether use of HA has improved their quality of life (QOL) or not, 83 of them $(85 \%)$ replied in affirmative, though only $64(65 \%)$ found the change appreciably good. 15 reported no change in QOL, 19 reported change less than expected, 55 reported change as per their expectation and 9 had change in QOL beyond expectation.

\section{Discussion}

HA benefit is broadly defined as the reduction in disability or handicap caused by a hearing loss (e.g., improved communication ability, increased participation in social activities) following amplification and/or aural rehabilitation. $^{2}$

HA benefit assessment may be subjective or objective. Objective way to assess is by comparing the aided and unaided speech reception thresholds and

Table III: Perceived difficulties of HA use

\begin{tabular}{|c|c|c|c|}
\hline PROBLEMS FACED WITH HA & \multicolumn{3}{|c|}{ FREQUENCY OF PROBLEMS } \\
\hline Wearing and removing it & Always & Sometimes & Never \\
\hline Handling the controls & Always & Sometimes & Never \\
\hline Problems with mould & Always & Sometimes & Never \\
\hline Noise of the aid itself & Always & Sometimes & Never \\
\hline Echo of own voice or swallowing & Always & Sometimes & 9 \\
\hline
\end{tabular}


Table IV: Satisfaction level with the technical features of $\mathrm{HA}$

\begin{tabular}{|c|c|c|c|}
\hline FEATURES OF HA & \multicolumn{2}{|c|}{ SATISFACTION LEVEL } \\
\hline Amplification & Amply satisfied & Satisfied & Not satisfied \\
\hline Noise cut & Amply satisfied & Satisfied & Not satisfied \\
\hline Clarity & Amply satisfied & Satisfied & Not satisfied \\
\hline Direction sense & Amply satisfied & Satisfied & Not satisfied \\
\hline Warranty & Amply satisfied & Satisfied & Not satisfied \\
\hline Battery life & Amply satisfied & Satisfied & Not satisfied \\
\hline $\mathbf{n}$ & 19 & 66 & 13 \\
\hline
\end{tabular}

speech recognition ability. Subjective way to assess is by analysing the response of the users as individual self reports. The degree to which a given hearing loss affects an individual's life is related to his lifestyle, occupation, academic concerns, psychological factors, etc. Hence, the hearing loss on audiogram may not always correspond to the degree of handicap experienced by the patient. Objective tests are done with a predefined external standard and are almost exclusively done in a laboratory which often fails to simulate realworld listening situations.

On the other hand, each individual harbours different expectations from the HA fitting. Hence, self report measures address the unique needs of all individuals and have become the new "gold standard" for measuring and reporting success. ${ }^{3}$ In the present study, outcomes were measured based on subjective levels of hearing satisfaction with respect to the clientele expectation, hours of daily use, benefit reaped, problems encountered, familiarity with the technological features and the change in the quality of life. Participants were predominantly fitted with digitally programmable HAs; monoaural BTE in cases of presbyacusis, binaural BTE in cases of soldiers and students, binaural ITC/CIC in young professionals and home makers. They were surveyed four and half months after fitting of HA.

Daily HA usage duration is important for adaptation to the device and hence success of its Application. ${ }^{4}$ The use of the HA for more than 4 hours a day is associated with significantly higher International outcome inventory for hearing aids (IOI-HA) scores, and individuals who use the HA more report greater benefits. ${ }^{5}$ In the present study, younger participants, primarily because of their needs, used the HA for more duration but at the same time they also reported excellent benefit. This was in contrast to the reports of study by Cox \& Alexander ${ }^{2}$ and Jerram \& Purdy. ${ }^{6}$

Individuals pursuing academics, managing domestic responsibilities, soldiers in active service and upwardly mobile professionals spelled out their obvious needs to overcome hearing disability. In elderly clientele, talking to family, interacting in close social circle, having telephonic conversation and watching television were the primary needs in order of priority to opt for HA.

The clientele's perceived benefit in their common domestic and social needs was assessed by an openended problems questionnaire, to which $85(87 \%)$ reported satisfactory benefit whereas $26(27 \%)$ reported good to excellent benefit. Most studies have found HAs to be beneficial. Bhat et $\mathrm{al}^{7}$ have reported $74 \%$ satisfaction level in a smaller sample size of 68 subjects whereas Kochkin ${ }^{8}$ and Bertoliet $\mathrm{al}^{9}$ have reported up to $80 \%$ in studies involving large samples consisting of 3174 and 8707 participants respectively.

This study revealed that only $9 \%$ individuals denied facing any difficulty with the device. Majority, $72 \%$ sometimes and $17 \%$ always, did complain about some problems with the device; the background noise and mould discomfort being the most common ones. Bhat et $\mathrm{al}^{7}$ reported that background noise (14\%) and difficulty in use with telephone $(13 \%)$ were the most common confounding factors in the use of HAs. Köjbleret al, ${ }^{10}$ have also reported that $16 \%$ of their subjects reported background noise as troublesome and 14\% reported 
ear mould discomfort. Disturbing background noise and wearing discomfort have been reported as the most common cause of non-use by Bertoliet al. ${ }^{9}$

It is important to make every beneficiary aware about the technological features of the HA prescribed to him/ her. The clientele uses the device more often and for longer duration and also takes more care of the device if he is conversant with the features. The knowledge makes him seek consultation as and when he encounters dissatisfaction with amplification, clarity, noise cut, directionality, battery life or warranty. In this study $13 \%$ were not at all satisfied with the features, they always faced difficulty in handling the aid, reported no benefit with its use and hence seldom used it.

Majority of hearing aid users in this study reported significant satisfaction level after fitting a hearing aid. An improvement in the listening power due to enhanced amplification, by itself, was not sufficient to make a client completely happy. Improved hearing ability, suitable sound quality, device reliability, usefulness in multiple listening environments, post-purchase service, and mould comfort were found to be more important factors influencing clientele satisfaction.

\section{Conclusion}

Majority of users reported significant satisfaction level with hearing aid. An improvement in the listening power due to enhanced amplification, by itself, was not sufficient to make a client completely happy. Improved hearing ability, suitable sound quality, device reliability, usefulness in multiple listening environments, postpurchase service, and mould comfort were reported to be more important factors influencing clientele satisfaction.

\section{References}

1. Gagné J. What is treatment evaluation research? What is its relationship to the goals of audiological rehabilitation? Who are the stakeholders of this type of research? Ear Hear 2000; 21(4):60S-73S

2. Cox RM, Alexander GC. Measuring Satisfaction with Amplification in Daily Life: the SADL scale. Ear Hear 1999; 20(4):306-20

3. Taylor B. Audiology Online Contributing Editor. Self-Report Assessment of HA Outcome - An Overview; 2007

4. Magni C, Freiberger F, Tonn K. Evaluation of satisfaction measures of analog and digital HA users. Braz J Otorhinolaryngol. 2005; 71(5): 650-7

5. Şahin H, Akın SO, Aydın E. Effects of the Unilateral HA on Hearing and Quality of Life in Adult Patients. J Otolaryngol ENT Res. 2015; 3(3): 00065. DOI: 10.15406/joentr. 2015. 03.00065

6. Jerram JC, Purdy SC. Technology, expectations, and adjustment to hearing loss: predictors of HA outcome. J Am Acad Audiol. 2001; 12:64-79

7. Bhat N, Shewale SS, Kasat PD, Tawade HS. Survey on HA use and satisfaction in patients with presbyacusis. Indian $\mathrm{J}$ Otol. $2015 ; 21: 124-8$

8. Kochkin S, Marke Trak VIII. Patients report improved quality of life with HA usage. The Hearing Journal 2011; 64:25-26, $28,30,32$

9. Bertoli S, Staehelin K, Zemp E, Schindler C, Bodmer D, Probst R. Survey on HA use and satisfaction in Switzerland and their determinants. Int J Audiol. 2009; 48:183-95

10. Köjbler S, Rosenhall U, Hansson H. Bilateral HAs - Effects and consequences from a user perspective. ScandAudiol. 2001; 30:223-35. 